Article

\title{
Determination of Vitamin B2 Content in Black, Green, Sage, and Rosemary Tea Infusions by Capillary Electrophoresis with Laser-Induced Fluorescence Detection
}

\author{
Filiz Tezcan * and F. Bedia Erim
}

Department of Chemistry, Istanbul Technical University, Maslak, Istanbul 34469, Turkey; erim@itu.edu.tr

* Correspondence: filiz.tezcan@acibadem.edu.tr; Tel.: +90-532-568-3669

Received: 18 October 2018; Accepted: 5 November 2018; Published: 10 November 2018

check for updates

\begin{abstract}
Vitamin B2, also known as riboflavin (RF) is an essential micronutrient for human health and must be obtained from dietary sources. Plants biosynthesize riboflavin and are important dietary sources of vitamin B2 for humans. Our present study reports sensitive detection of vitamin B2 in widely consumed tea infusions, namely black, green, sage and rosemary tea infusions, by a capillary electrophoresis method combined with laser induced fluorescence detection. Moreover, the correlation between the vitamin B2 content of tea plants with their total phenolics (TPs) and antioxidant capacity are evaluated in this study. Whereas green teas have the highest TPs and antioxidant capacity, the highest RF content is in sage infusions. The RF content ranged between 0.34 and $10.36 \mu \mathrm{g} / \mathrm{g}$ for all tea samples studied. Comparing the RF content of tea samples found in this study to the RF content of known RF sources, tea infusions are proposed as important dietary sources of vitamin B2.
\end{abstract}

Keywords: tea; Salvia officinalis; Rosmarinus officinalis; total phenolic; antioxidant

\section{Introduction}

Tea from the leaves of the Camellia sinensis plant is the most widely consumed drink in the world, after water. There are three kinds of tea products produced from the same plant: Black (fermented), green (not fermented) and oolong (partially fermented) teas. The tea leaves are dried, crushed and left for fermentation. Fermentation is a natural process and oxidation during fermentation is caused by a natural enzyme in the tea leaves themselves. While green tea is not fermented, black tea is subjected to full fermentation and the color of the tea leaves change to black. Tea is adietary source of many bioactive compounds. Both black and green tea contain bioactive phenolic compounds mainly gallic, trans-cinnamic, caffeic, ferulic, p-coumaric acids, catechin, epicatechin, quercetrin, and caffeine [1,2]. However their content differs with different processing levels of tea samples. Several chemo metric studies have been developed for tea identification based on the bioactive ingredients and antioxidant activities of tea samples [1,2]. The health benefit effects of tea on cancer and cardiovascular diseases, to obesity and diabetes were extensively reviewed by Khan and Mukhtar [3]. Afzal et al. reviewed the potential therapeutic role of epigallocatechin gallate, which is the main constituent of green tea [4]. It was shown that this compound is associated with antitumor, anti-Alzheimer, and anti-aging properties. Heber et al. reported that all three tea polyphenol extracts induced weight loss and had anti-inflammatory and angiogenic effects [5].

In 2010, world tea production reached over 4.52 million tons [6]. Turkey is the fifth largest producer of tea in the world after China, India, Kenya and Sri Lanka [7]. Furthermore, Turkey has one of the highest per capita black tea consumption rates in the world. The attention given to green tea 
in Turkey has been increasing due to its effect against obesity. Sage (Salvia officials) tea is one of the most popular herbal teas in Turkey. Like black and green teas, sage and rosemary contain many health beneficial bioactive compounds [8,9].

Riboflavin (RF), or its commonly known name vitamin B2, is a water-soluble vitamin and essential for human health. RF must be obtained from foods since it cannot be synthesized or stored in the body. Vitamin B2 deficiency affects many organs and tissues [10]. Milk, dairy products, meat, fish, dark-green vegetables, and some beverages like beer and wine are important sources of this vitamin. The analysis of RF in food samples is difficult because of the complex matrix of food and very low content of RF in foodstuffs. Recently, capillary electrophoresis (CE) has received great attention in food analysis due to its easy method, development availability, low sample consumption, fast analysis times, and inexpensive separation columns [11]. Lately, a combination of laser induced fluorescence (LIF) detectors with capillary electrophoresis has provided a remarkable improvement in detection limits. Since RF has a native fluorescence, the RF content of various foods have been studied by capillary electrophoretic methods using LIF detection [12-17].

Although a significant number of studies have been reported on tea, sage, and rosemary phenolics, almost no information exists concerning the vitamin content of these plants. Hu and coworkers reported vitamin B2 in two green tea samples [14]. To our knowledge, there is no study on the content of vitamin B2 in sage and rosemary. The aim of this study is to contribute to the information on the nutritional value of widely consumed tea infusions, by determining the vitamin B2 content of tea plants using the CE-LIF method. Moreover, the correlation between the vitamin B2 content of tea plants with their total phenolics and antioxidant capacity are evaluated in this study.

\section{Materials and Methods}

\subsection{Materials}

Riboflavin, Folin-iocalteu reagent, gallic acid, 2,4,6-tripyridyl-s-triazine and $\mathrm{FeCl}_{3} \cdot 6 \mathrm{H}_{2} \mathrm{O}$ were from Sigma Chemical Co. (Steinheim, Germany). Di-sodium hydrogen phosphate dehydrates, sodium carbonate anhydrous, sodium acetate trihydrate, and $\mathrm{FeSO}_{4} \cdot 7 \mathrm{H}_{2} \mathrm{O}$ were from Merck (Darmstadt, Germany). All solutions were prepared with water purified by an ElgaPurelab Option-7-15 model system (Elga, UK).

Four Black (B1-B4) and two green (G1 and G2) tea-bag samples were obtained from local markets inIstanbul as known commercial brands. The B1 sample consisted of teas from the East Black Sea region of Turkey. The others were tea blends. According to the labels, B2 was a blend of Kenyan and Sri Lankan teas. B3 was a blend of Turkish, Kenyan, and Indonesian teas. B4 was a blend of Turkish, Sri Lankan, Kenyan, and Indian teas. Sage and Rosemary samples were purchased from Istanbul (S1, S2, R1 and R2) and Boston (S3, S4, R3 and R4) markets as known commercial brands.

\subsection{Method}

Separations were performed with an Agilent capillary electrophoresis system (Waldbronn, Germany) equipped with a ZETALIF 2000 LIF detector (Picometrics, Montlaur, France). RF was detected with an excitation of $488 \mathrm{~nm}$ and emission of $520 \mathrm{~nm}$ by an Ar-ion laser. The data processing was carried out with the Agilent ChemStation software. The separation was performed at $25 \mathrm{kV}$. The temperature was set at $25{ }^{\circ} \mathrm{C}$. Injections were made at 50 mbar for $6 \mathrm{~s}$. The fused-silica capillary used for separation experiments was $50 \mu \mathrm{m}$ ID and was obtained from Polymicro Technologies (Phoenix, AZ, USA). The total length of the capillary was $67 \mathrm{~cm}$ and the length to the detector was $50 \mathrm{~cm}$. The new fused-silica capillary was conditioned prior to use by rinsing with $1 \mathrm{M} \mathrm{NaOH}$ for $30 \mathrm{~min}$ and with water for $10 \mathrm{~min}$. The capillary was flushed successively by $0.1 \mathrm{M} \mathrm{NaOH}$ for $2 \mathrm{~min}$, water for $2 \mathrm{~min}$, and buffer for $5 \mathrm{~min}$, at the beginning of every working day and between runs.

Tea leaves were placed in a pot containing boiling water and the pot was incubated in a water bath for $5 \mathrm{~min}$. Incubation time was optimized by checking the degradation of riboflavin standard in hot 
water vs. time, as explained in Results. After filtration of tea leaves from the hot water, tea infusions were directly injected in to the capillary column.

\subsection{Determination of Total Phenolics (TPs)}

The total phenolics of each infusion were determined by using the Folin-Ciocalteu method [18]. For each type of infusion, $300 \mu \mathrm{L}$ was mixed with $1.5 \mathrm{~mL}$ of Folin-Ciocalteu's reagent (1:10 diluted with water) and $1.2 \mathrm{~mL}$ of sodium carbonate solution $(7.5 \% \mathrm{w} / \mathrm{v})$. The mixture was allowed to stand for $10 \mathrm{~min}$ at room temperature until a stable color was obtained. The absorbance of $1 / 10$ fold diluted samples were measured by a Shimadzu UV-1800 spectrophotometer (Shimadzu Scientific Instruments, North America) at $760 \mathrm{~nm}$. Results were expressed as gallic acid equivalents (GAE) in $\mathrm{mg} / \mathrm{g}$. The calibration equation for gallic acid was $\mathrm{y}=49.582 \mathrm{x}-0.0185\left(\mathrm{R}^{2}=0.995\right)$.

\subsection{FRAP Assay}

The ferric-reducing antioxidant power (FRAP) of the infusions was determined, following the method of Benzie and Strain [19]. The FRAP reagent was prepared containing 1:1:10 ratio of $10 \mathrm{mM}$ 2,4,6-tripyridyl-s-tri-azine (TPTZ) solution in $40 \mathrm{mM} \mathrm{HCl}, 20 \mathrm{mM} \mathrm{FeCl}_{3}$ and $0.3 \mathrm{M}$ acetate buffer at $\mathrm{pH} 3.6$, and warmed to $37^{\circ} \mathrm{C}$ for $10 \mathrm{~min}$. prior to use. The mixture containing $100 \mu \mathrm{L}$ sample, $100 \mu \mathrm{L}$ deionized water, and $1.8 \mathrm{~mL}$ FRAP reagent was incubated at $37^{\circ} \mathrm{C}$ for $10 \mathrm{~min}$. The absorbance of the 1/10 fold diluted mixture was measured by a Shimadzu UV-1800 spectrophotometer at $593 \mathrm{~nm}$. Results were expressed as $\mu \mathrm{mol} \mathrm{Fe} \mathrm{F}^{+2} / \mathrm{g}$. The calibration equation for $\mathrm{FeSO}_{4} \cdot 7 \mathrm{H}_{2} \mathrm{O}$ was $y=20.044 x-0.0373\left(R^{2}=0.999\right)$.

\subsection{Statistical Analysis}

The statistical analysis was applied to the RF content, TPs, and FRAP values of tea samples. The significant differences between the mean values with $p<0.05$ were evaluated by a one way analysis (ANOVA) test and the Duncan's new multiple range test using XLSTAT 2017 (Data Analysis and Statistical Solution for Microsoft Excel. Addinsoft, Paris, France (2017)).

\section{Results and Discussion}

\subsection{Optimization of Separation}

Since the pKa value of RF is 9.69, the molecule gains a negative charge in basic solutions and can migrate under an electrical field. Phosphate electrolyte was selected as the separation medium. When the phosphate concentration was changed between 15 and $75 \mathrm{mM}$, no significant change was observed in peak shapes. On the other hand, while the $\mathrm{pH}$ of separation electrolyte increased, the RF peak separated from the electroosmotic peak (negative water peak) and was easily integrated. The fluorescence intensity of RF was maximum at pH 9.9. Finally, $30 \mathrm{mM}$ phosphate at $\mathrm{pH} 9.9$ was selected as the optimal medium for separation and detection.

\subsection{Optimization of Extraction}

$\mathrm{RF}$ is slightly soluble in water. One g dissolves in 3-15 L water, depending on the crystal structure (Sigma-Aldrich, Steinheim, Germany). RF is heat stable but very sensitive to light [20]. Considering the very small content of RF in food products, it can be expected that hot water will withdraw the RF in tea leaves. In order to check the stability of RF in hot water vs. time, a RF standard was dissolved in hot water $\left(100^{\circ} \mathrm{C}\right)$. This solution was left in a water bath for different times and riboflavin content of these solutions was determined by the CE-LIF method. Figure 1 shows the comparative results. 


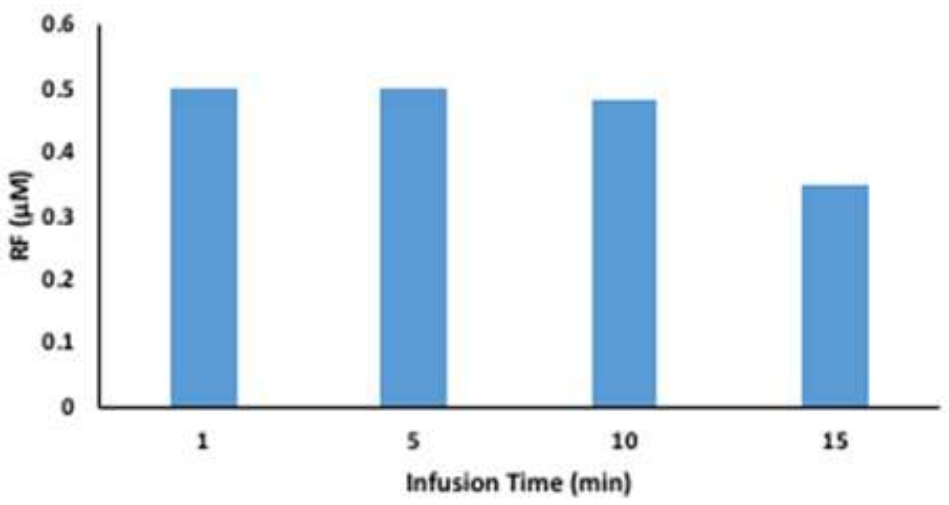

Figure 1. Riboflavin amount in hot water vs. infusion time.

As seen from Figure 1, at the end of the 5 min incubation time, we did not observe any decrease in RF concentration in hot water. The decrease of RF content with time after $5 \mathrm{~min}$ is probably due to light sensitivity of the molecule. Thereby, $5 \mathrm{~min}$ was applied as the optimal incubation time for all tea infusions. $50 \mathrm{~mL}$ of boiling water was poured on $1 \mathrm{~g}$ of tea leaves and the pot was incubated in a water bath for $5 \mathrm{~min}$. In fact, this is the traditional tea brewing method in homes and coffee houses in Turkey, and $5 \mathrm{~min}$ is the accepted time to obtain a good tea infusion.

After filtration of tea leaves from hot water, tea infusions were directly injected in to the capillary column. Figure 2 shows a representative electropherogram of one sage herbal tea infusion (S3). As seen from the electropherogram, the RF peak came in less than $4 \mathrm{~min}$. Since infusions were directly injected without any purification or derivatization step, the analysis method of RF was very short and simple.

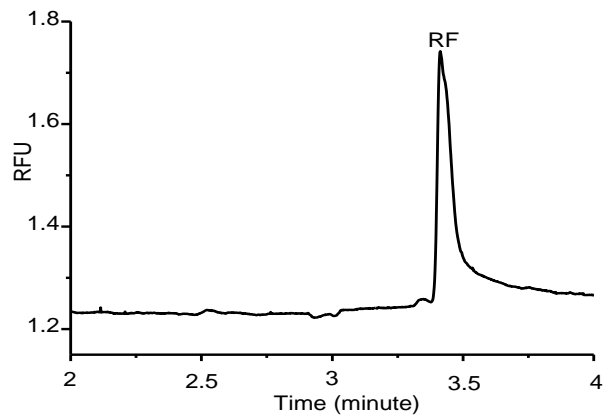

Figure 2. Electropherogram of $1 / 2$ diluted sage herbal tea (S3). Conditions: $50 \mu \mathrm{m} \times 50 \mathrm{~cm}$ capillary, 50 mbar 6 s injection, $25 \mathrm{kV}$ running voltage, $30 \mathrm{mM}$ phosphate buffer at $\mathrm{pH}$ : 9.9.

\subsection{CE Method Validation}

The calibration curve of RF was linear between $0.01-5 \mu \mathrm{M}$ concentration ranges. The calibration equation was calculated as $y=0.9544 x-0.0375\left(R^{2}=0.999\right)$. The limit of dedection (LOD) value was obtained from the software of the CE instrument. The calculation was based on the LOD valuebeingthe concentration corresponding to the baseline average noise of electropherogram taken from three different baseline areas. The LOD of the method for RF was found as $1.08 \mathrm{ng} / \mathrm{mL}$. The limit of quantification (LOQ) was given as ten times the average noise as $3.58 \mathrm{ng} / \mathrm{mL}$. For testing the precision of the method, the RF standard solution was injected 5 times in one day. For day-to-day reproducibility, the same solution was injected five times in three different non-consecutive days. In the same day, precision of the corrected peak areas (\%RSD; relative standart deviation) was $2.48 \%$. Between days, the precision value was $4.58 \%$.

The recovery experiments were done with one herbal tea sample. The infusion was spiked with standard RF solution atthree different spike levels at the beginning of the extraction process. Satisfactory recovery for RF was obtained as between 99.7 and $106 \%$. 


\subsection{Riboflavin Content of Tea Samples}

The RF content of tea infusions are given as the averages of three infusions with their standard deviations in Table 1.

Table 1. RF content of tea infusions (B: Black, G: Green, S: Sage, R: Rosemary).

\begin{tabular}{|c|c|c|c|}
\hline & $\begin{array}{c}\text { RF } \\
(\mu \mathrm{g} / \mathrm{g} \pm \mathrm{SD}) \text { * }\end{array}$ & & $\begin{array}{c}\text { RF } \\
(\mu g / g \pm S D) *\end{array}$ \\
\hline B1 & $3.34 \pm 0.19^{d}$ & S1 & $5.36 \pm 0.72 e^{e}$ \\
\hline B2 & $0.58 \pm 0.16^{a b c}$ & S2 & $5.22 \pm 0.29^{\mathrm{e}}$ \\
\hline B3 & $1.57 \pm 0.06^{b c}$ & S3 & $6.18 \pm 0.31^{\mathrm{e}}$ \\
\hline B4 & $1.07 \pm 0.05^{\mathrm{abc}}$ & S4 & $10.36 \pm 0.79^{f}$ \\
\hline G1 & $3.26 \pm 0.46^{\mathrm{d}}$ & R1 & $2.87 \pm 0.06^{\mathrm{d}}$ \\
\hline \multirow[t]{3}{*}{ G2 } & $2.80 \pm 0.10^{\mathrm{d}}$ & $\mathbf{R} 2$ & $0.42 \pm 0.08^{a b}$ \\
\hline & & R3 & $1.72 \pm 0.35^{\mathrm{c}}$ \\
\hline & & R4 & $0.34 \pm 0.01^{\mathrm{a}}$ \\
\hline
\end{tabular}

* Means \pm standard deviations. Different letters in the same lines are significantly different at the $5 \%$ level $(p<0.05)$.

As seen from Table 1, the RF content changes between 0.34 and $10.36 \mu \mathrm{g} / \mathrm{g}$ for all tea samples. Amongst the tested black tea samples, the B1 sample which contains tea leaves fromthe East Black Sea region of Turkey was found to have the richest RF content. The RF content of the blends tested are smaller than in this tea. The RF content of two green tea samples were higher compared to the RF content of black teas. The RF content of rosemary samples were rather similar to the RF content of black tea blends. However, the RF content of all sage teas were substantially higher than those of black and green teas, and rosemary infusions. S4 especially contained significantly higher RF.

\subsection{Total Phenolics (TPs) and Antioxidant Capacities}

The TPs and FRAP values of tea infusions are given in Table 2. TPs ranged from 4.91 to $114 \mathrm{mg}$ GAE/g dry tea leaves for all tea types tested. Green tea samples hadthe highest TPs compared to both black tea and herbal tea samples.

Table 2. The TPs and FRAP values of tea infusions. (B: Black, G: Green, S: Sage, R: Rosemary).

\begin{tabular}{|c|c|c|}
\hline & TPs (mg GAE/g \pm SD) * & FRAP $\left(\mu \mathrm{mol} \mathrm{Fe}{ }^{+2} / g \pm \mathrm{SD}\right) *$ \\
\hline B1 & $73.55 \pm 2.33^{c}$ & $462.3 \pm 0.6^{b}$ \\
\hline B2 & $94.21 \pm 1.59^{\mathrm{e}}$ & $491.8 \pm 4.2^{b}$ \\
\hline B3 & $67.71 \pm 1.68^{\mathrm{d}}$ & $449.2 \pm 3.7^{b}$ \\
\hline B4 & $91.39 \pm 1.99 \mathrm{e}$ & $479.4 \pm 10.2^{b}$ \\
\hline G1 & $113.6 \pm 1.9^{\mathrm{f}}$ & $601.4 \pm 56.1^{\mathrm{d}}$ \\
\hline G2 & $112.8 \pm 1.8^{\mathrm{f}}$ & $551.5 \pm 17.5^{\mathrm{c}}$ \\
\hline S1 & $16.86 \pm 0.15^{b}$ & $64.64 \pm 8.65^{\mathrm{a}}$ \\
\hline $\mathrm{S} 2$ & $17.14 \pm 0.10^{\mathrm{b}}$ & $65.08 \pm 2.00^{\mathrm{a}}$ \\
\hline S3 & $17.27 \pm 0.13^{b}$ & $78.44 \pm 2.22^{\mathrm{a}}$ \\
\hline S4 & $17.97 \pm 0.2^{b}$ & $81.86 \pm 0.32^{\mathrm{a}}$ \\
\hline R1 & $17.16 \pm 0.62^{b}$ & $81.34 \pm 3.81^{\mathrm{a}}$ \\
\hline R2 & $4.91 \pm 0.06^{\mathrm{a}}$ & $63.84 \pm 0.84^{\mathrm{a}}$ \\
\hline R3 & $17.14 \pm 0.23^{b}$ & $76.62 \pm 1.37^{\mathrm{a}}$ \\
\hline R4 & $5.19 \pm 0.02^{\mathrm{a}}$ & $65.89 \pm 0.84^{\mathrm{a}}$ \\
\hline
\end{tabular}

* Means \pm standard deviations. Different letters in the same lines are significantly different at the $5 \%$ level $(p<0.05)$.

The FRAP values of the tested teas ranged between $449-492 \mu \mathrm{mol} / \mathrm{g}$ for black tea samples and 552-601 $\mu \mathrm{mol} / \mathrm{g}$ for green tea samples. Benzie and Szeto reported FRAP values for 25 types of teas, ranging between 132-654 $\mu \mathrm{mol} / \mathrm{g}$ for black teas and 272-1144 $\mu \mathrm{mol} / \mathrm{g}$ for green teas [21]. The FRAP values for black and green tea infusions found in this study are in agreement with these reported FRAP 
values. The antioxidant capacities of sage and rosemary teas ranged between $63.8-81.9 \mu \mathrm{mol} / \mathrm{g}$ for 8 herbal tea infusions.

TPs and the antioxidant capacities of black and green tea infusions are obviously higher than those of herbal tea infusions. As expected, there is a strong correlation (0.985) between TPs and the antioxidant capacities of all tea infusions tested in this study. However, there is no correlation between TPs or antioxidant capacity and RF content of teas. Whereas green teas have the highest TPs and antioxidant capacity, the highest RF content was determined to be in sage infusions.

$\mathrm{Hu}$ and coworkers reported 2.8 and $5.4 \mu \mathrm{g} / \mathrm{g}$ RF for two green tea samples, which is in agreement with our reported values [14]. RF content of several foods have been reported in the literature. Cataldi et al. have reported the RF content of 8 vegetables ranging between $0.34-1.67 \mu \mathrm{g} / \mathrm{g}$ [12]. The RF content in five milk samples having different animal origins were reported to be between 101 and $175 \mu \mathrm{g} / 100 \mathrm{~mL}$, in 2 white wine samples as 12 and $13 \mu \mathrm{g} / 100 \mathrm{~mL}$, in raw egg white as $3.8 \mu \mathrm{g} / \mathrm{g}$, and in raw egg yolk as $3.2 \mu \mathrm{g} / \mathrm{g}$ [13]. The RF in 12 commercial beers was reported as $13-28 \mu \mathrm{g} / 100 \mathrm{~mL}$ [15]. The RF content of honeys was reported to change in a wide range as from non-detectable to $18.04 \mu \mathrm{g} / \mathrm{g}$ [16]. RF content of five saffron samples from two of the biggest producers in the global market (Iran and Spain) were reported in the range of 5.02-13.86 $\mu \mathrm{g} / \mathrm{g}$ [17].

Assuming a tea brew obtained from $2 \mathrm{~g}$ of dry tea (around the mass of dry tea in one tea bag) and $200 \mathrm{~mL}$ of hot water (the volume of a tea mug), our reported RF values for dry tea samples of $0.34-10.36 \mu \mathrm{g} / \mathrm{g}$ correspond to $0.34-10.36 \mu \mathrm{g} R / 100 \mathrm{~mL}$ infusion. When the RF content of tea samples found in this study are compared to the RF content of green vegetables, milk, egg, wine, beer, honey, and saffron samples, known as important RF sources, it can be seen that tea infusions are also important dietary sources of vitamin B2.

\section{Conclusions}

A fast, simple, and sensitive CE-LIF system was used to determine the riboflavin (vitamin B2) content of 14 tea infusions including black, green, sage, and rosemary teas. The RF content of all tea samples suggests that tea infusions are amongst important dietary sources of RF for prevention of diseases caused by vitamin B2 deficiency.

Author Contributions: Both of theauthors designed the experiments; F.T. has done experiments and also calculated-analyzed the data; F.T. wrote the manuscript; F.B.E. supervised the research and wrote and edited the manuscript.

Funding: This research received funding from the Research Foundation of Istanbul Technical University.

Conflicts of Interest: The authors declare no conflict of interest.

\section{References}

1. Azevedo, R.S.A.; Teixeira, B.S.; Sauthier, M.C.D.; Santana, M.V.A.; Dossantos, W.N.L.; Santana, D.D. Multivariate eanalysis of the composition of bioactive in tea the species Camellia sinensis. Food Chem. 2019, 273, 39-44. [CrossRef] [PubMed]

2. Zielinski, A.A.F.; Haminniuk, C.W.I.; Alberti, A.; Nogueira, A.; Demiate, I.M.; Granato, D. A comparative srudy of the phenolic compounds and the in vitro antioxidant activity of different Brazilian teas using multivariate statistical techniques. Food Res. Int. 2014, 60, 246-254. [CrossRef]

3. Khan, N.; Mukhtar, H. Tea polyphenols for health promotion. LifeSci. 2007, 81, 519-533. [CrossRef] [PubMed]

4. Afzal, M.; Safer, A.M.; Menon, M. Green tea poly phenols and their potential role in health and disease. Inflammopharmacology 2015, 23, 151-161. [CrossRef] [PubMed]

5. Heber, D.; Zhang, Y.J.; Yang, J.P.; Ma, J.E.; Henning, S.M.; Li, Z.P. Green tea, black tea, and oolong tea polyphenols reduce visceral fat and inflammation in mice fed high-fat, high-sucrose obesogenic diets. J. Nutr. 2014, 144, 1385-1393. [CrossRef] [PubMed]

6. FAOSTAT. 2010. Available online: http:/ / faostat.fao.org (accessed on 8 September 2018).

7. WORLDATLAS. Available online: https://www.worldatlas.com/articles/the-worlds-top-10-tea-producingnations.html (accessed on 22 September 2018). 
8. Başkan, S.; Öztekin, N.; Erim, F.B. Determination of carnosic acid and rosmarinic acid in sage by capillary electrophoresis. Food Chem. 2007, 101, 1748-1752. [CrossRef]

9. Topcu, G. Bioactive triterpenoids from Salvia species. J. Nat. Pro. 2006, 69, 482-487. [CrossRef] [PubMed]

10. Powers, H.J. Riboflavin (vitamin B-2) and health. Am. J. Clin. Nutr. 2003, 77, 1352-1360. [CrossRef] [PubMed]

11. Castro-Puyana, M.; Garcia-Canas, V.; Carolina, S.; Cifuentes, A. Recent advances in the application of capillary electromigration methods for food analysis and Foodomics. Electrophoresis 2012, 33, 147-167. [CrossRef] [PubMed]

12. Cataldi, T.R.I.; Nardiello, D.; Carrara, V.; Ciriello, R.; De Benedetto, G.E. Assessment of riboflavin and flavin content in common food samples by capillary electrophoresis with laser-induced fluorescence detection. Food Chem. 2003, 82, 309-314. [CrossRef]

13. Cataldi, T.R.I.; Nardiello, D.; De Benedetto, G.E.; Bufo, S.A. Optimizing separation conditions for riboflavin, flavin mononucleotide and flavin adenine dinucleotide in capillary zone electrophoresis with laser-induced fluorescence detection. J. Chromatogr. A 2002, 968, 229-239. [CrossRef]

14. Hu, L.; Yang, X.; Wang, C.; Yuan, H.; Xiao, D. Determination of riboflavin in urine and beverages by capillary electrophoresis with in-column optical fiber laser-induced fluorescence detection. J. Chromatogr. B 2007, 856, 245-251. [CrossRef] [PubMed]

15. Su, A.K.; Chang, Y.S.; Lin, C.H. Analysis of riboflavin in beer by capillary electrophoresis/blue light emitting diode (LED)-induced fluorescence detection combined with a dynamic $\mathrm{pH}$ junction technique. Talanta 2004, 64, 970-974. [CrossRef] [PubMed]

16. Kaygusuz, H.; Tezcan, F.; Erim, F.B.; Yıldız, O.; Şahin, H.; Can, Z.; Kolaylı, S. Characterization of Anatolian honeys based on minerals, bioactive components and principal component analysis. LWT-Food Sci. Technol. 2016, 68, 273-279. [CrossRef]

17. Hashemi, P.; Erim, F.B. Analysis of vitamin B2 in saffron stigmas (Crocus sativus L.) by capillary electrophoresis coupled with laser-induced fluorescence detector. Food Anal. Methods 2016, 9, 2395-2399. [CrossRef]

18. Singleton, V.L.; Rossi, J.L. Colorimetry of total phenolics with phosphomolybdic-phosphotungstic acid reagents. Am. J. Enol. Vitic. 1965, 16, 144-158.

19. Benzie, I.F.F.; Strain, J.J. The ferric reducing ability of plasma (FRAP) as a measure of "antioxidant power": The FRAP assay. Anal. Biochem. 1996, 239, 70-76. [CrossRef] [PubMed]

20. Choe, E.; Huang, R.; Min, D.B. Chemical reactions and stability of riboflavin in foods. J. Food Sci. 2005, 70, R28-R36. [CrossRef]

21. Benzie, I.F.F.; Szeto, Y.T. Total antioxidant capacity of teas by the ferric reducing/antioxidant power assay. J. Agric. Food Chem. 1999, 47, 633-636. [CrossRef] 